\title{
MITOS KEBUDAYAAN DALAM FILM JAWARA KIDUL, TINUK DAN KTP: ANALISIS SEMIOLOGI BARTHESIAN
}

\author{
Oleh: \\ Vani Dias Adiprabowo, M. Sn \\ Program Studi Ilmu Komunikasi \\ Universitas Ahmad Dahlan, Jl. Ring Road Selatan, Bantul, Daerah Istimewa Yogyakarta \\ 55191 \\ E-mail: vani.adiprabowo@comm.uad.ac.id
}

\begin{abstract}
Abstrak
Film Jawara Kidul, Tinuk dan KTP adalah tiga pemenang kategori umum Festival Video Edukasi (FVE) 2016. Ketiga film tersebut dikaji dengan teori semiologi Roland Barthes untuk mengungkap perihal mitos atau wacana yang berusaha dibangun oleh film tersebut melalui tanda-tanda kebudayaan. Dalam hal ini, film dianggap sebagai produk budaya karena memproduksi dan mereproduksi tanda maupun wacana kebudayaan. Selain itu juga, film dianggap sebagai alat komunikasi publik dalam menyampaikan pesan melalui tanda-tanda kebudayaan. Penelitian ini menggunakan metode kualitataif yang berusaha mengungkap makna dalam fenomena kebudayaan, serta memahami pengalaman dan pemikiran manusia. Selain itu, penelitian ini menggunakan sudut pandang konstruktivisme budaya, yang menganggap bahwa budaya merupakan bentukan secara sosial dan politik. Maka dari itu, budaya kerap diandaikan sebagai wacana dan mitos. Hasil dari penelitian ini menunjukkan bahwa film Jawara Kidul berusaha untuk membangun mitos kesaktian dan kejantanan yang menunjukkan adanya wacana dominasi laki-laki. Film ini membangun wacana Jawara yang laki-laki, jantan, sakti sekaligus relijius. Sedangkan film Tinuk berusaha membangun mitos kelas sosial, yang menyajikan wacana kelas sosial bawah dan kelas sosial atas. Masyarakat kelas sosial bawah kemudian tak sanggup untuk membeli barang kelas menengah atas. Terakhir yakni film KTP, yang berusaha untuk membangun mitos negara. Dalam film tersebut, negara diwacanakan sebagai pihak pengayom yang berusaha membantu persoalan masyarakat, khususnya kelas sosial bawah. Negara juga diwacanakan ikut terlibat aktif dalam bermusyawarah bersama warga masyarakat.
\end{abstract}

Kata Kunci: Budaya, Mitos, Dominasi, Kelas Sosial dan Negara

\begin{abstract}
Film Kidul, Tinuk and KTP are the winners of Education Video Festival (FVE), general category, in 2016. The films are analyzed by Roland Barthes' semiology theory to reveal myth or discourse constructed in the films by means of cultural signs. In his case,
\end{abstract}


film is regarded as cultural product for producing and reproducing cultural signs and discourse. Film also plays role as public communication to convey message by means of cultural signs. This research uses qualitative method which tries to reveal meaning in cultural phenomena and also to understand human thoughts and experiences. This research also uses constructivism perspective which views culture as socially and politically constructed. Therefore culture tends to assume as discourse and myth. The result shows that Jawara Kidul film tries to construct myth of magic and masculine which show man's domination. This film construct the winner as a man, masculine and religious. Then Tinuk film tries to construct myth of social class which presents discourse low class and high-middle class. Low class people cannot buy a thing from high-middle class. The last is KTP film which tries to construct myth of state. In this film, state is constructed as protector who tries helping to solve people's problem, especially low class people. State is also constructed as an active participant to have discussion with people/society.

\section{Keywords: Culture, Myth, Domination, Social Class and State}

\section{A. PENDAHULUAN}

Keprihatinan terhadap program acara televisi yang kebanyakan menyuguhkan hiburan dengan unsur pendidikan dan lokalitas yang minim, melahirkan inisiatif-inisiatif dari para video/film maker untuk membuat video/film sebagai media alternatif untuk publik. Karya-karya video/film tersebut tertampung dalam Festival Video Edukasi (FVE). Video/film dalam FVE mengedepankan tema-tema pendidikan. Dalam hal ini, nilai-nilai pendidikan akan lebih mudah dicerna dalam bentuk audio-visual. Video/film menjadi alat komunikasi dalam menyampaikan pesan-pesan pendidikan sekaligus. Video/film yang tertampung dalam FVE akan digunakan untuk mensukseskan program pendidikan pemerintah, dalam hal ini Kementrian Pendidikan dan Kebudayaan (Kemdikbud).

FVE diselenggarakan oleh Balai Pengembangan Media Televisi (BPMTP), yang merupakan salah satu unit pelaksana teknis di lingkungan Pusat Teknologi Informasi dan Komunikasi (Pustekkom), Kementrian Pendidikan Nasional dan Kebudayaan. FVE pertama kali diadakan pada tahun 2007, dengan tema "Kita Ciptakan Karya Video Edukasi yang Santun dan Mencerdaskan untuk Menyukseskan Program Pendidikan untuk Semua. FVE pertama terdiri dari tiga kategori antara lain pendidikan budi pekerti, pendidikan luar biasa untuk tuna rungu dan filler pendidikan. Di setiap penyelenggaraannya, FVE mengusung tema yang berbeda sekaligus kategori yang juga terus berinovasi. FVE merupakan usaha dalam menjawab tantangan pendidikan di zaman sekarang, dengan berkreasi dan berinovasi dalam bentuk video/film.

Mulai tahun 2016, FVE berinovasi dengan membuat kategori baru yakni program video pembelajaran khusus untuk guru. Program video pembelajaran ini menampung video mata pelajaran IPA dengan sasaran siswa SMP. Kategori program ini dimaksudkan untuk memudahkan siswa memahami pelajaran di sekolah, serta diharapkan mampu meningkatkan kualitas dan kuantitas video pembelajaran sekolah. 
Di tahun 2016, FVE mengangkat tema "Insan Indonesia Hebat dan Berbudi Luhur”, dengan kategori peserta: Pelajar (SMP-SMA), Mahasiswa, Guru dan Umum. Tulisan ini mengkaji film-film pemenang FVE tahun 2016. Secara khusus, tulisan ini meneliti film-film pemenang kategori umum, yakni tiga (3) film berjudul Jawara Kidul, KTP dan Tinuk. Tiga film tersebut akan dianalisis dengan menggunakan teori semiologi untuk mengetahui makna yang terkandung dalam simbol-simbol yang ditampilkan dalam film. Secara khusus, tulisan ini hendak mengungkap makna dari simbol-simbol kebudayaan dari tiga film tersebut. Dari sudut pandang ilmu komunikasi, film menjadi sarana komunikasi kepada publik. Dalam hal ini, film tersebut punya misi komunikasi pendidikan kepada publik. Maka dari itu, untuk memahami pesan yang disampaikan dalam film, maka diperlukan pembacaan secara visual. Visual, dalam hal ini, mewujud dalam simbol/ tanda yang tampil di film. Dari sudut pandang kebudayaan, film menjadi sarana yang memproduksi dan mereproduksi tanda-tanda kebudayaan. Oleh sebab itu, film turut dianggap sebagai produk budaya itu sendiri.

\section{B. TINJAUAN PUSTAKA}

Semiologi merupakan ilmu yang mempelajari bahasa secara struktural. Bahasa, dalam hal ini, dimaknai sebagai sistem tanda. Tokoh yang mempelopori semilogi yakni Ferdinand de Saussure. Bagi Sausuure, bahasa sebagai struktur tersusun atas tanda-tanda. Artinya, Sausure menganggap tanda sebagai satuan bahasa, yang ketika disusun dan dirangkai akan menghasilkan makna. Saussure (1959:65-66) membagi tanda menjadi dua, yakni penanda dan petanda. Penanda adalah bentuk materi dari tanda, yang berupa visual/citra-bunyi. Sedangkan petanda adalah konsep abstraknya. Tanda-tanda mesti disusun berdasarkan aturan tertentu supaya ia bisa bermakna. Aturan tersebut, menurut Saussure, yakni sintagmatik dan paradigmatik. Sintagmatik merupakan aturan kombinasi/relasi antar tanda. Tanda-tanda, dalam aturn kombinasi, bersifat ada atau hadir. Sedangkan paradigmatik adalah seleksi tanda-tanda yang digunakan dalam susunan/kombinasi. Tanda-tanda yang diseleksi bersifat absen, tidak muncul. Hanya hasil pilihan atau tanda yang terpilih yang muncul atau hadir. Makna dalam kajian semiologi didapatkan dari pembacaan tanda-tanda berdasarkan struktur, sistem dan aturannya.

Pemikiran Saussure tentang semiologi kemudian dikembangkan oleh seorang ahli bahasa, Roland Barthes. Jika Saussure membaca makna tanda secara struktural, maka Barthes menawarkan pembacaan tanda secara historis. Bahasa sebagai suatu sistem tanda mendapatkan makna historisnya ketika dituturkan dalam konteks tertentu. Berbagai cara penuturan itulah yang disebut Barthes sebagai mitos. Mitos merupakan tipe tuturan yang antara lain berupa fotografi, film, video, lukisan, musik dengan menggunakan tanda-tanda kebudayaan. Bagi Barthes, mitos mendapatkan maknanya dalam konteks historis tertentu. Mitos berada dalam sistem tanda kedua. 


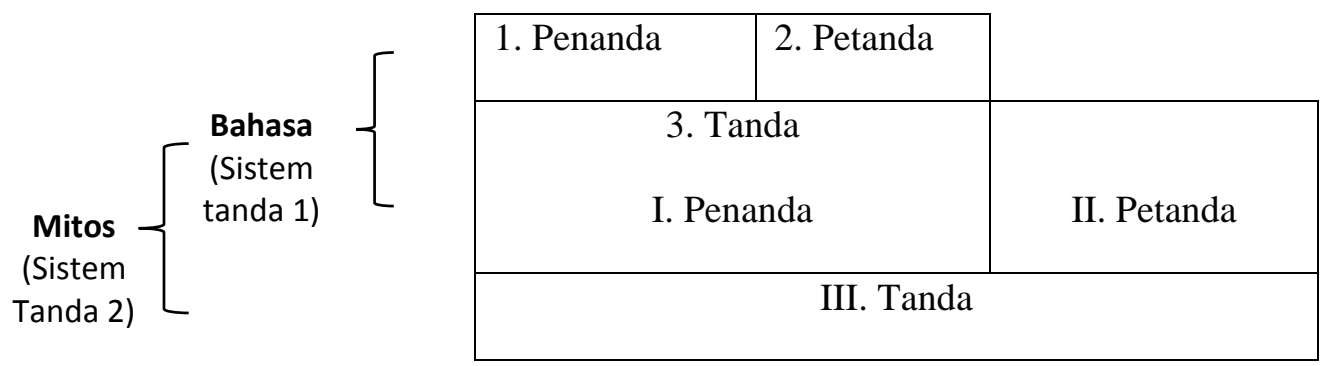

(Barthes 1972:113)

Sistem tanda pertama berlaku pada pembacaan tanda secara struktural, yang mengandaikan hubungan penanda (1) dan petanda (2) dalam suatu sistem bahasa. Tanda (3) dalam sistem tanda pertama menjadi penanda dalam sistem tanda kedua. Sedangkan penanda mendapat petanda atau konsepnya dari konteks sejarah. Hubungan penanda dan petanda dalam sistem tanda kedua adalah kontraktual atau berdasarkan konvensi sosiokultural.

Model analisis budaya kaitannya dengan semiologi ditawarkan oleh Geertz. Baginya, konsep budaya adalah jejaring tanda-tanda, maka dari itu kebudayaan menggunakan tafsir atau interpretasi dalam mengungkap maknanya (Geertz, 1973:5). Budaya turut diaggap terbentuk secara sosial, yang juga menunjukkan bahwa tanda-tanda budaya merupakan ekspresi sosial masyarakat.

\section{METODOLOGI}

Tulisan ini membahas film dari sudut pandang komunikasi dan kebudayaan. Untuk memahami fenomena kebudayaan, maka digunakan metode penelitian kualitatif. Dalam hal ini, penelitian kualitatif menekankan pada bagaimana mengungkap suatu fenomena kaitannya dengan pengalaman, pemikiran serta pemahaman manusia terhadap konteks lingkungannya (Denzin, N.K. dan Lincoln, Y.S., 2009:598). Metode penelitian kualitatif sesuai dengan riset kebudayaan yang menekankan pada pemahaman akan kehidupan manusia. Dalam penelitian ini, film dianggap sebagai produk kebudayaan perihal bagaimana manusia memahami realitas. Pemahaman akan realitas atau dunia tesebut kemudian tertuang dalam produk film.

Untuk memahami perihal bagaimana budaya bekerja, maka diperlukan sudut pandang kebudayaan. Dalam hal ini, sudut pandang konstruktivisme digunakan untuk menganalisis fenomena kebudayaan sebagai konstruksi sosial. Sudut pandang konstruktivisme menganggap kebudayaan tidak terbentuk secara natural, namun dibentuk secara sosial dan politis (Hall, 1997:25-26). Dalam hal ini, film yang diteliti merupakan alat komunikasi yang membentuk/mengkonstruksi kebudayaan melalui simbol ataupun tanda-tanda. Film memiliki sifat kreatif. Maka kreativitas dalam film merupakan usaha menyusun pengetahuan, pemahaman, pemikiran, ide dan gagasan dengan menggunakan variabel-variabel komunikatif. Supaya bisa menyampaikan pesan dengan baik, maka tanda- 
tanda kebudayaan digunakan sebagai strategi penyampaian. Tanda-tanda itulah yang akan dianalisis dalam tulisan ini.

Perihal seleksi data, beberapa film yang dipilih didasarkan pada kode budaya yang bersifat lokal. Selain itu, pemilihan data didasarkan pada tingkat kreativitas karya film. Maka dari itu, data yang dikaji dalam penelitian ini adalah para pemenang FVE kategori umum. Tiga film pemenang tersebut dianggap mewakili kualitas dan kreativitas yang baik dari para peserta FVE. Pemilihan tahun 2016, karya video pemenang FVE, dimaksudkan untuk memproduksi karya ilmiah yang bersifat kekinian, yang mencoba membaca karya film terbaru yang tersedia dari para pemenang FVE.

\section{PEMBAHASAN}

Tiga film pemenang FVE 2016, yakni berjudul Jawara Kidul, KTP dan Tinuk. Ketiganya menggunakan simbol atau tanda budaya dalam menyampaikan pesan-pesan pendidikan. Video berjudul Jawara Kidul mendapat juara 3 (karya terbaik 3) kategori umum. Tinuk mendapat juara 2 (karya terbaik 2) kategori umum. Sedangkan KTP meraih juara pertama (karya terbaik 1) kategori umum FVE 2016.

\section{Mitos Jawara Laki-laki}

Film Jawara Kidul banyak menggunakan simbol atau tanda budaya tradisional. Dalam hal ini, penggunaan simbol memang dimaksudkan sebagai atribut dan perlengkapan yang mendukung latar (setting) cerita perihal pertarungan kedua pendekar, kakak-adik, dalam memperebutkan Nyimas Ayu. Cerita juga berlatar waktu zaman dahulu. Namun, tanda selain berperan sebagai atribut dan perlengkapan, ia juga bermakna kultural.
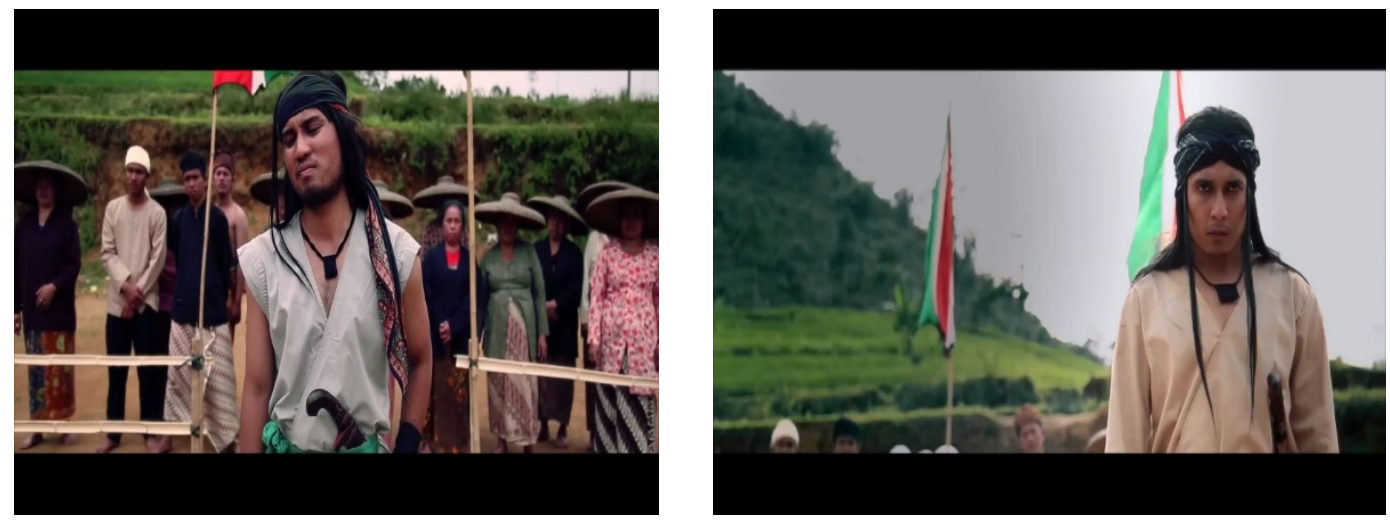

Gambar sebelah kiri yang berada di tengah-depan adalah tokoh Sakti, sedangkan gambar sebelah kanan adalah tokoh Prabu. Kedua gambar tersebut menunjukkan beberapa tanda antara lain ikat kepala, kalung, pelindung tangan dan senjata tajam (golok). Tandatanda kebudayaan tersebut berusaha untuk membangun mitos kejantanan atau maskulinitas dari masing-masing tokoh. Selain itu juga, tanda-tanda budaya tradisional tersebut berusaha untuk membangun mitos kesaktian dari masing-masing tokoh. Mitos kejantanan dan kesaktian dibangun dalam tokoh laki-laki dengan tanda budaya tradisional, yang turut 
membentuk wacana tentang dominasi laki-laki. Dalam film itu juga, sang tokoh perempuan Nyimas Ayu hanya berposisi sebagai tokoh yang diperebutkan oleh Jawara.

Tanda budaya lokal dalam film Jawara Kidul turut berusaha untuk membangun mitos norma baik-buruk, tokoh baik-jahat, penyelamat-penjahat. Kedua konstruksi wacana yang saling bertentangan tersebut muncul dengan simbol-simbol budaya yang berbeda seperti ditunjukkan dalam cuplikan adegan berikut.
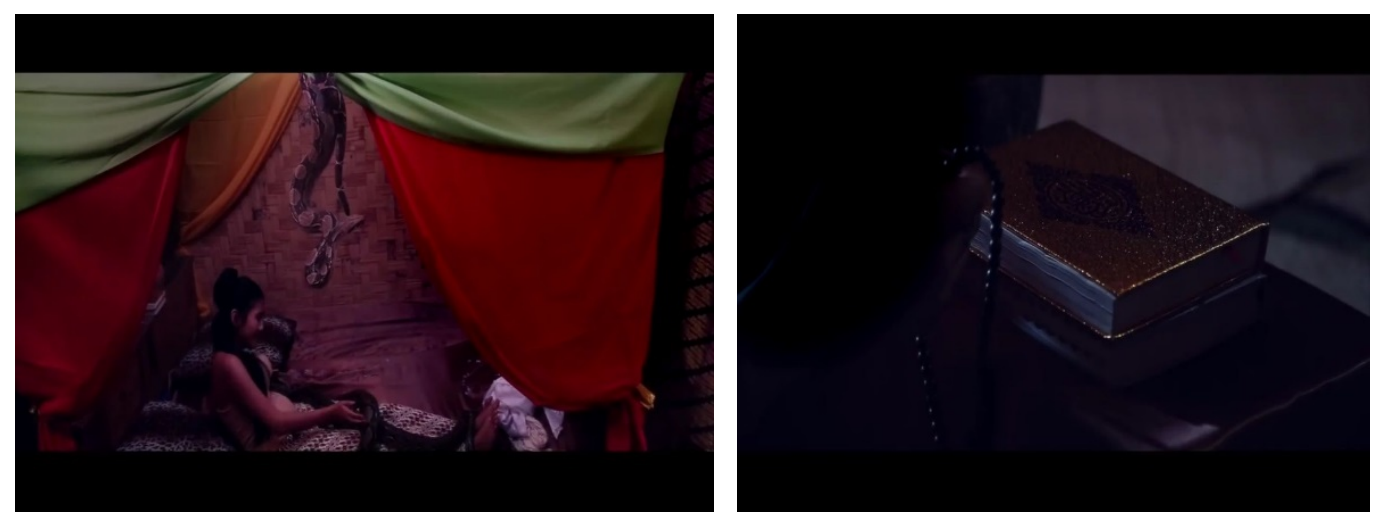

Cuplikan gambar adegan sebelah kiri adalah kiriman ular-ular dari Sakti untuk menyerang Nyimas Ayu. Sedangakan gambar sebelah kanan adalah tangan Prabu sedang memegang tasbih dan disampingnya ada Al-Quran yang digunakan untuk menangkal serangan ular Sakti. Simbol ular di sini bermaksud untuk membangun mitos kejahatan, yang mampu membunuh orang dengan jeratannya. Dalam hal ini, Sakti sebagai pelakunya turut digambarkan sebagai tokoh jahat dengan simbol ular tersebut. Sedangkan tanda tasbih dan Al-Quran yang menjadi pegangan Prabu hendak membangun mitos kebaikan, yang sanggup menangkal kejahatan. Dalam hal ini, tokoh Prabu turut dibangun menjadi tokoh penyelamat dengan simbol tersebut. Pada akhirnya, yang jahat mampu dikalahkan oleh yang baik. Jawara Kidul adalah Prabu dengan mitos kejantanan, kesaktian, kebaikan sekaligus relijius. Pada akhirnya, wacana mampu membentuk identitas tertentu. Hall (1990:225) menyebutnya sebagai identitas budaya, yakni pemahaman akan identitas sebagai konstruuksi sejarah, budaya dan sosial, yang bersifat dinamis dan mengandung relasi kuasa. Dalam film Jawara Kidul identitas laki-laki tebentuk melalui wacana kejantanan, kesaktian serta relijius, yang kemudian mengandung kuasa dominasi laki-laki.

\section{Mitos Kelas Sosial}

Film berikutnya yakni Tinuk. Film ini bercerita peihal seorang istri bernama Tinuk yang kerap mengeluh karena kondisi hidupnya dengan suaminya yang serba kesulitan dalam memenuhi kebutuhan hidup. Sang suami tidak mau korupsi atau mengambil uang yang bukan haknya, meskipun hidupnya kekurangan. Film Tinuk banyak menggunakan atribut yang biasa digunakan oleh kalangan keluarga kelas bawah. 

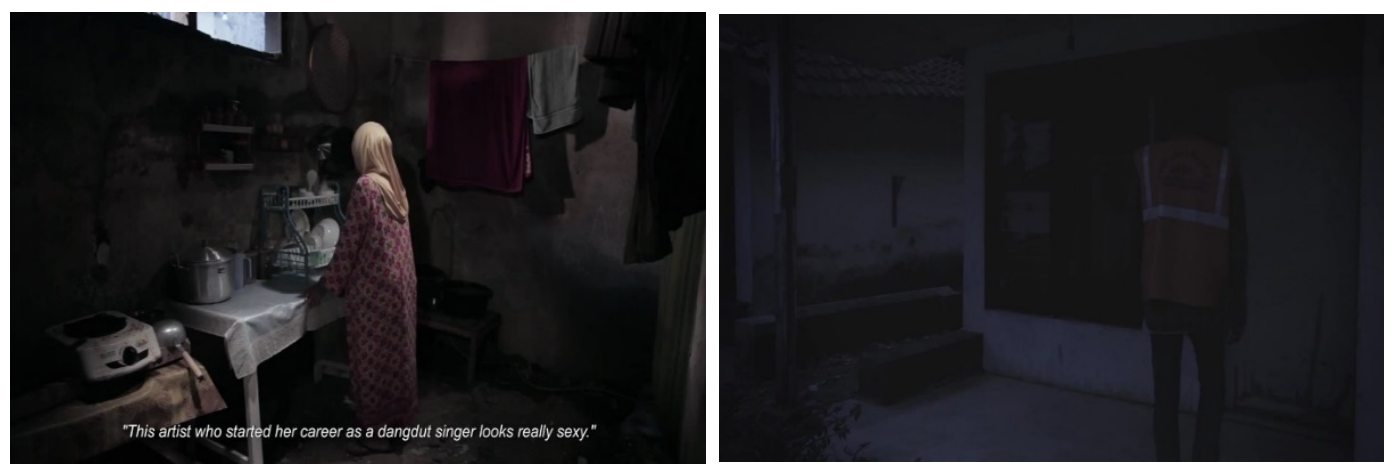

Gambar sebelah kiri adalah tokoh Tinuk sedang berada di dapur. Sedangkan gambar sebelah kanan adalah bagian depan rumah dan suami Tinuk yang hendak masuk ke rumahnya. Gambar sebelah kiri menghadirkan tanda-tanda antara lain baju, celana, handuk yang digantung serta peralatan dapur, tembok retak serta lantai tanah. Tanda-tanda tersebut berusaha membangun mitos kemiskinan. Begitu juga dengan gambar sebelah kanan yang menunjukkan tanda-tanda rumah Tinuk dengan pintu yang mengelupas, tiang kayu yang retak-terbelah. Tanda-tanda tersebut turut membangun mitos ‘hidup susah' dari keluarga kelas bawah.

Tokoh Tinuk dalam kondisi awal yang kekurangan kemudian bertemu dengan Maskur yang menawarkan barang Handphone. Tinuk sangat menginkan barang HP tersebut, maka ia terus membujuk suaminya untuk membelikannya, sambil terus mengeluh tentang kondisi hidupnya dengan suami.
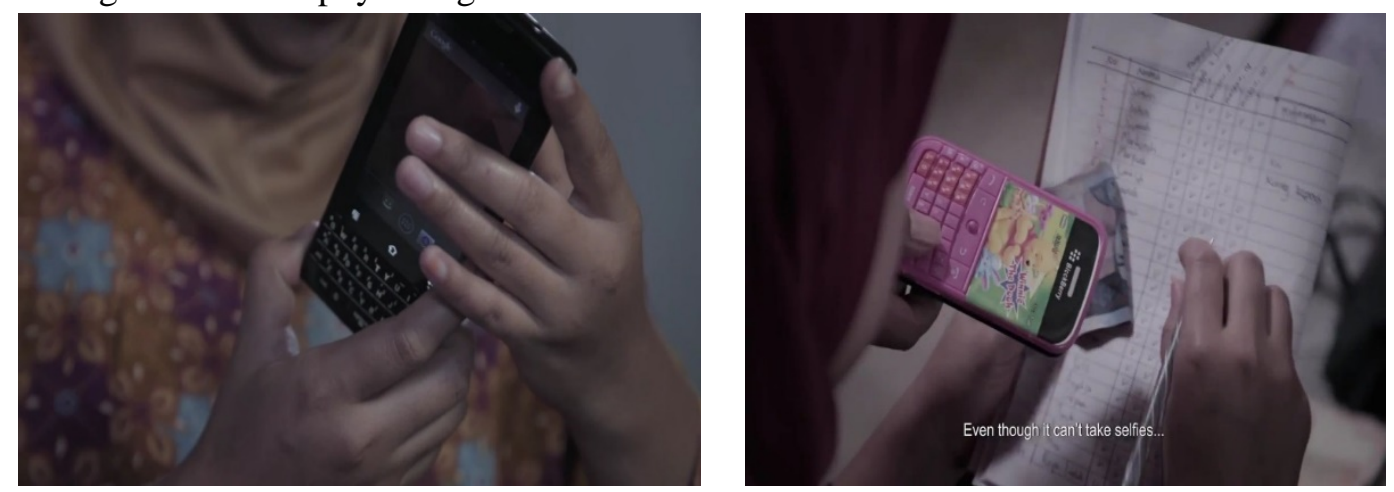

Gambar sebelah kiri menunjukkan barang HP yang ditawarkan oleh Maskur kepada Tinuk. Tanda berupa barang HP bisa ditafsir sebagai tanda kelas menengah-atas. Dalam cerita juga, Tinuk yang membujuk suaminya tidak mampu membeli barang HP tersebut. Hal ini juga menandakan adanya subjek kelas bawah yang tak mampu membeli barang kelas menengah atas. Sedangkan gambar di sebelah kanan menunjukkan HP mainan yang diberikan oleh suami kepada Tinuk. Dalam hal ini, HP mainan tersebut menandakan mitos kelas bawah. Barang HP mainan tersebut juga berusaha membangun mitos humoris dan kekanak-kanakan. 


\section{Mitos Negara}

Selanjutnya yakni film KTP. Film ini bercerita perihal seorang pegawai kecamatan, Darno, yang hendak meminta data pada Mbah Karsono untuk pembuatan KTP, yang nantinya bisa digunakan untuk mengurus kartu jaminan kesehatan. Darso mengunjungi rumah Mbah Karsono yang pelosok dan mengalami kesulitan meminta data Mbah Karsono, karena ia tidak ingat umur dan tanggal lahirnya. Serta Mbah Karsono meyakini agama Kejawen yang tidak termasuk dalam kategori 6 pilihan agama dalam KTP.
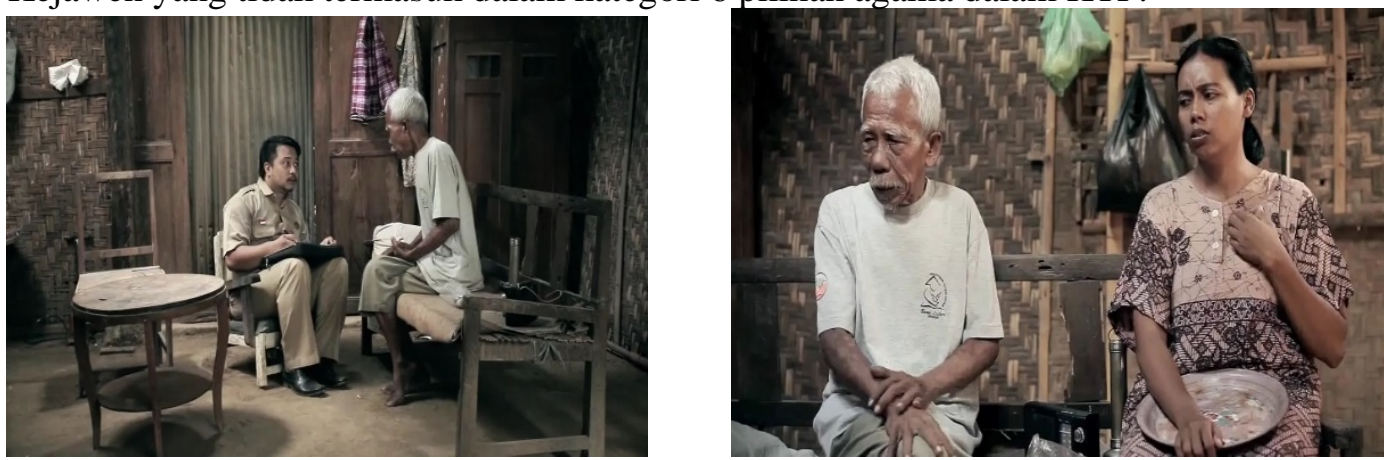

Gambar sebelah kiri menunjukkan Darso yang sedang berbincang dengan Mbah Karsono untuk meminta data. Sedangkan gambar sebelah kanan menunjukkan Mbah Karsono dan Nunung, tetangganya yang berusaha membantu menyelesaikan kesulitan mendapatkan data tersebut. Tanda seragam yang dipakai Darso mewakili pihak Negara. Sedangkan Mbah Karsono dengan tanda berupa pakaian lusuh dan rumah gedek mewakili orang tua yang miskin. Tokoh Nunung, dengan tanda pakaian daster dan nampan yang lusuh turut mendukung keterwakilan masyarakat desa yang kurang mampu. Tanda-tanda tersebut berusaha membangun mitos kehadiran negara pada masyarakat kelas bawah. Dalam hal ini, negara berusaha memberikan bantuan kepada masyarakat kelas bawah.

Kesulitan mendapatkan data dari mbah Karsono membutuhkan peran dari Pak RT dan Pak Harso sebagai ketua Badan Musyawarah Desa untuk urun rembug dalam menyelesaikan masalah. Tak hanya mereka, tetapi persoalan ini turut mengundang wargawarga sekitar untuk turut bermusyawarah dalam menyelesaikan masalah mbah Karsono. Mereka semua kumpul di rumah Mbah Karsono.
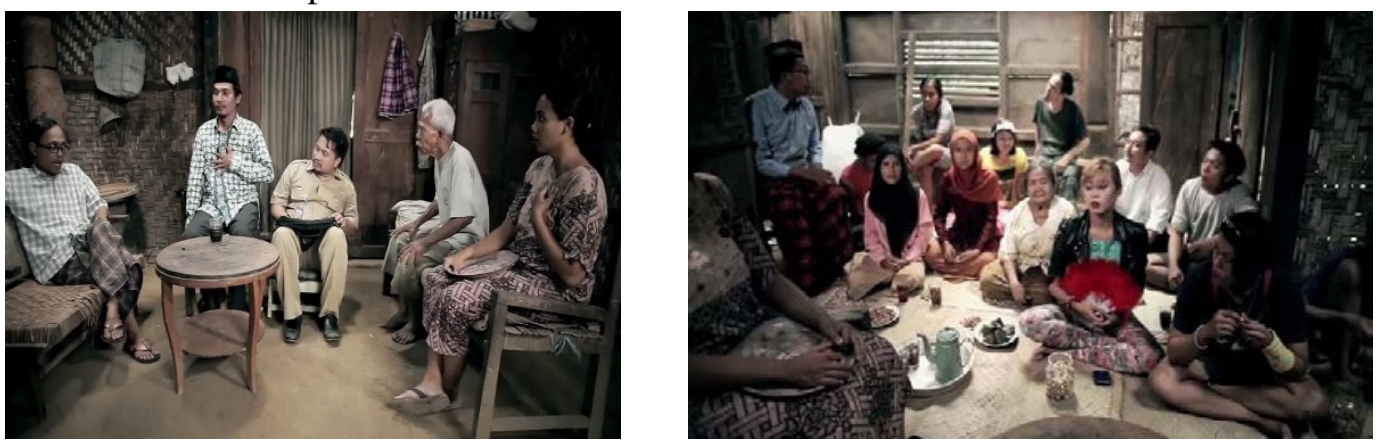

Gambar sebelah kiri menunjukkan Nunung, Mbah Karsono, Darso, Pak RT dan Pak Harso yang sedang berdiskusi perihal masalah data dan jaminan kesehatan untuk mbah Karso. Sedangkan gambar sebelah kanan menunjukkan para warga sekitar yang turut bermusyawarah. Tanda-tanda yang hadir secara visual dari kedua gambar tersebut berusaha 
membangun mitos kehadiran negara untuk berkumpul dan menyelesaikan persoalan masyarakat. Serta tanda-tanda tersebut berusaha untuk membangun wacana keterlibatan aktif negara dalam bermusyawarah dengan masyarakat kalangan bawah. Meskipun di akhir cerita, mbah Karsono tidak lagi membutuhkan jaminan kesehatan dari negara karena para warga sekitar mau membantu mengurus mbah Karsono, tetapi keterlibatan negara tetap ada diantara masyarakat, yang menunjukkan perhatiannya kepada masyarakat khususnya golongan kelas bawah.

\section{E. KESIMPULAN}

Tiga film pemenang FVE 2016, yakni KTP. Tinuk dan Jawara Kidul, masingmasing memiliki cara tersendiri dalam menyajikan tanda-tanda kebudayaan untuk sarana penyampaiann pesan pendidikan. Dalam hal ini, video merupakan produk kebudayaan, karena ia turut memproduksi dan mereproduksi tanda dan makna kebudayaan. Video juga menjadi alat komunikasi kepada publik, yang dalam hal ini, mampu menjawab inovasi strategi dalam menghadapi tantangan kemajuan zaman dan teknologi. Dalam tafsir kebudayaan, tiga vdeo tersebut masing-masing memproduksi mitos atau wacana kebudayaan yang berbeda-beda.

Film Jawara Kidul, melalui tanda-tanda atrbut berupa pakaian, kalung, pelindung pergelangan tangan dan senjata yang dipakai oleh tokoh laki-laki, Prabu dan Sakti, memproduksi wacana kejantanan, kesaktian dan dominasi laki-laki. Simbol ular dalam film tersebut memproduksi kejahatan, sedangkan kebaikan diproduki melalui tanda tasbih dan Al-Quran. Pada akhirnnya kejahatan mampu dikalahkan dengan kebaikan. Yang baik, Prabu, pada akhirnya jadi Jawara yang sakti, jantan dan relijius. Sedangkan film Tinuk mencoba memproduksi mitos kelas sosial. Dalam hal ini, Tinuk dan suaminya mewakili masyarakat kelas sosial bawah. Tanda berupa barang HP memproduksi mitos kelas menengah-atas. Dalam hal ini, kelas sosial bawah pada akhirnya tak sanggup membeli barang kelas menengah atas. Terakhir, film KTP memproduksi mitos Negara. Dalam film tersebut, negara diwacanakan hadir dalam membantu masyarakat kelas bawah. Negara juga dibangun sebagai pihak yang mengayomi masyarakat. Dalam hal ini, negara melakukan tugas untuk terlibat aktif untuk bermusyawarah dengan masyarakat khususnya kelas bawah dalam menyelesaikan masalah-masalah di masyarakat. 


\section{DAFTAR PUSTAKA}

Barthes, Roland, 1972, Mythologies, New York:The Noonday Press.

Denzin, N.K. dan Lincoln, Y.S., 2009, Handbook of Qualitative Research, Yogyakarta:Pustaka Pelajar.

Geertz, Clifford, 1973, The Interpretation of Cultures, New York:Basic Books, Inc.

Hall, Stuart (Ed), 1997, Representation, London:Sage Publications.

Hall, Stuart, 1990, “Cultural Identity and Diaspora”, Jurnal Framework, No 36, hal. 222237.

Saussure, Ferdinand de, 1959, Course in General Linguistics, New York:Philosophical Library.

\section{Sumber lain}

fve.kemdikbud.go.id 